\title{
Erratum to: Population genetic analysis of hyacinth bean (Lablab purpureus (L.) Sweet, Leguminosae) indicates an East African origin and variation in drought tolerance
}

\author{
Oliver Robotham • Mark Chapman (iD)
}

Received: 5 August 2015/Accepted: 12 October 2015/Published online: 7 January 2016

(C) Springer Science+Business Media Dordrecht 2016

\section{Erratum to: Genet Resour Crop Evol DOI 10.1007/s10722-015-0339-y}

We regret we acknowledged the seed from the USDA and IITA, and it actually came from the USDA and ILRI.

The Acknowledgments should have read:

\section{Materials and methods}

Plant material and DNA extraction

A collection of seed (Online Resource 1) was obtained from the USDA National Plant Germplasm System (http://www.ars-grin.gov/npgs/index.html) and the ILRI Germplasm Collection (https://www.ilri.org/).
Ninety-one geographically diverse accessions were germinated in a mixture of $1 / 3$ vermiculite: $2 / 3 \mathrm{Lev}-$ ington's $\mathrm{F} 2+\mathrm{S}$ compost in a greenhouse at $23{ }^{\circ} \mathrm{C}$ and a 16-h photoperiod. Plants were placed on flood benches which were flooded twice a day for $15 \mathrm{~min}$. Seven and four accessions represented subsp. bengalensis and subsp. uncinatus, respectively, with the remaining 80 representing the main cultivated group, subsp. purpureus. Accessions mentioned in the text have six digits if they came from the USDA and five digits if they were sourced from ILRI.

Acknowledgments This study was funded by the University of Southampton for OR to carry out an undergraduate project in the laboratory of MAC. We are grateful to the genebanks at the USDA and ILRI for their assistance in providing the seed material and to the Department of Zoology, University of Oxford, for carrying out the sequencing and genotyping.

The online version of the original article can be found under doi:10.1007/s10722-015-0339-y.

O. Robotham · M. Chapman ( $₫)$

Centre for Biological Sciences, University of

Southampton, Southampton SO17 1BJ, UK

e-mail: m.chapman@soton.ac.uk

M. Chapman

Centre for Underutilised Crops, University of

Southampton, Southampton SO17 1BJ, UK 